\section{Journal of Behavioral} Addictions

$10(2021) 2,327-337$

DOI:

10.1556/2006.2021.00035

(c) 2021 The Author(s)

\title{
Prosocialness in young males with substance and behavioral addictions
}

\author{
ALEXANDER TOMEI $^{1 *}$ (@), JOSEPH STUDER ${ }^{1}$ and \\ GERHARD GMEL ${ }^{1,2,3,4}$
}

\author{
${ }^{1}$ Addiction Medicine, Department of Psychiatry, Lausanne University Hospital and University of \\ Lausanne, Rue du Bugnon 23, CH - 1011 Lausanne, Switzerland \\ ${ }^{2}$ Research Department, Addiction Switzerland, Lausanne, Switzerland \\ ${ }^{3}$ Centre for Addiction and Mental Health, Institute for Mental Health Policy Research, Toronto, ON, \\ Canada \\ ${ }^{4}$ Department of Health and Social Sciences, University of the West of England, Bristol, UK
}

Received: September 29, 2020 • Revised manuscript received: February 23, 2021 • Accepted: May 15, 2021 Published online: June 30, 2021

\section{FULL-LENGTH REPORT}

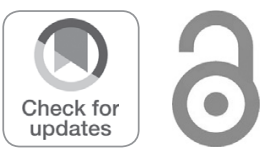

\begin{abstract}
Background and aims: Social determinants are closely related to addiction, both as a cause and a consequence of substance use and other addictive behaviors. The present paper examines prosocialness (i.e. the tendency to help, empathize, and care for others) among a population of young males. We compared prosocialness across different types of addiction and examined whether prosocialness varied according to the presence of multiple addictions. Methods: A sample of 5,675 young males, aged 19-29 years old (Mean $=21.4$; Median $=21$ ), completed a questionnaire that included screening tools to identify addictive behaviors with regards to alcohol, nicotine, cannabis, gambling, and gaming. The questionnaire also included a scale to measure prosocialness. Results: Compared to a no-addiction control group, the subgroups of young men suffering from behavioral addictions (i.e., gambling and gaming) reported the lowest levels of prosocialness. Respondents with an alcohol addiction also showed lower prosocialness compared to no-addiction controls. By contrast, no significant differences in prosocialness were found between respondents with nicotine disorder or cannabis disorder and the noaddiction controls. Furthermore, the number of addictions had no clear, observable effects on prosocialness. Significant differences were found between the no-addiction control group and the groups reporting one or more addictions, but not between the separate groups reporting one, two, and three or more addictions. Discussion and conclusions: A better understanding of the social dimension affecting young males with addiction, particularly gambling and gaming addictions, may be useful for their prevention and treatment.
\end{abstract}

\section{KEYWORDS}

substance addictions, behavioral addictions, prosocial behaviors, emerging adulthood, males

\section{INTRODUCTION}

Social relations are the essence of human life. From mother-infant bonding, throughout childhood and adolescence, and on into adulthood, relating to others is the basis of an individual's social adaptation and functioning. Impairments to the ability to process and implement social behaviors may result in social maladaptation (Cotter et al., 2018) and social withdrawal (Porcelli et al., 2019). Indeed, these impairments are characteristic of several clinical conditions (Cotter et al., 2018), including substance-related and behavioral addiction (Black, Shaw, McCormick, \& Allen, 2012; Cowlishaw, Suomi, \& Rodgers, 2016; Tomei, Besson, \& Grivel, 2017). As such, social behaviors may be prognostic of social adjustment (Caprara, Steca, Zelli, \& Capanna, 2005). In the present study, we examine prosocial responses in youths with substance-related and behavioral addictions. 
A consideration of the social dimension is highly relevant to an understanding of addictive disorders. The social environment plays a key role in every stage of the addiction process, from initiation to maintenance and from reduction to cessation (Cousijn, Luijten, \& Feldstein Ewing, 2018). Moreover, as with psychoactive substances or other addictive behaviors (e.g., gaming, gambling), the social environment can be a powerful source of reward. Neuroscience has shown that the brain's dopamine-based reward system is at the core of the addiction process (Volkow, Koob, \& McLellan, 2016), but it is also a key neural circuit in the processing of social cognitions (Pelloux, Giorla, Montanari, \& Baunez, 2019; Young, Gobrogge, \& Wang, 2011) and behaviors such as cooperation, caregiving, and altruism (Filkowski, Cochran, \& Haas, 2016; Moll et al., 2006; Preston, 2013). A dopaminebased neural circuit's function is to signal what is valuable to the individual concerned (Schultz, 2016). In addition, the value associated to specific objects or events at a particular moment in life may diminish as other objects or events become more valuable to that individual (Granfield \& Cloud, 2001). The effects of a highly rewarding substance or behavior (e.g., gambling) may thus dominate the natural rewards obtained from social interactions (Tomek \& Olive, 2018; Volkow, Baler, \& Goldstein, 2011). As an example, animal experiments showed that administering benzodiazepine midazolam to rats reduced their helping behaviors toward a trapped conspecific (Ben-Ami Bartal et al., 2016). Of course, the opposite process may also occur. Social bonding and caring for others may lower the perceived value of addiction-related rewards (Ferris et al., 2005; Liu, Young, Curtis, Aragona, \& Wang, 2011) and contribute to natural recovery (Granfield \& Cloud, 2001). For instance, Liu et al. (2011) demonstrated that amphetamine's rewarding properties induced conditioned place preference (CPP) in sexually naive prairie voles, but not in conspecifics with pair-bonding experience. Moreover, Fritz et al. (2011) showed that four 15min social interactions with a conspecific inhibited both cocaine-paired CPP and the drug's induced reinstatement. With this in view, training prosocial behaviors may counteract the rewarding effects of drugs through the enhancement of social skills (Volkow et al., 2016).

Although researchers examining addiction are becoming increasingly aware of the importance of social dimensions, data about the relationships between social dimensions and addiction remain limited. A number of studies have investigated empathy in populations with addictive disorders. Empathy is a basic socio-cognitive ability that enables an individual to understand others' experiences (Decety, 2010). Indeed, empathy has been observed to be lower among subjects with substance-related addictions to alcohol (Martinotti, Di Nicola, Tedeschi, Cundari, \& Janiri, 2009; Maurage et al., 2011), cocaine (Hulka, Preller, Vonmoos, Broicher, \& Quednow, 2013; Preller et al., 2014), methamphetamine (Homer et al., 2008), and opioids (Ferrari, Smeraldi, Bottero, \& Politi, 2014; Tomei, Besson, Reber, Rougemont-Bücking, \& Grivel, 2017). Reduced empathy has also been observed in behavioral addictions to gambling
(Tomei, Besson, \& Grivel, 2017), gaming (Hui, Wu, \& Pun, 2019), and the internet (Lachmann et al., 2018).

The question has thus arisen as to whether prosocial responding might also be one of the socio-cognitive impairments in people with addiction. Prosocial responding, subsumed under the general term of prosocialness, refers to the capacity to both empathize with others and enact subsequent prosocial behaviors (Caprara et al., 2005). Prosocial behaviors play a fundamental role in social adaptation since they contribute to the giving-receiving equilibrium that is inherent to all human relations and societies (Gouldner, 1960). In line with the principle of reciprocity (Gouldner, 1960), people mutually exchange behaviors that are intended to benefit others (Batson \& Powell, 2003). Moreover, prosocial behaviors have positive effects on individuals' welfare. They have been shown to be protective against mental disorders (Caprara et al., 2005), to improve self-esteem (Barber \& Erickson, 2001) and well-being (Anik, Aknin, Norton, \& Dunn, 2009; Post, 2005), and to increase the perception of meaning in life (Klein, 2017). In addition, prosocialness has been shown to reduce the likelihood of engaging in substance use (Carlo, Crockett, Wilkinson, \& Beal, 2011). Finally, providing prosocial behaviors have been shown to be beneficial to individuals with addictive disorders. For instance, members of Alcoholics Anonymous who help other members to maintain their abstinence from alcohol are less likely to relapse themselves in the year following treatment (Pagano, Friend, Tonigan, \& Stout, 2004).

Thus, considering that empathy plays a pivotal role in the development of prosocial behaviors (Bethlehem et al., 2016; Decety, Bartal, Uzefovsky, \& Knafo-Noam, 2016; Lockwood, Apps, Valton, Viding, \& Roiser, 2016) and that it has been shown to be lower in several substance-related and behavioral addictions, we expect prosocialness to be lower in populations with addictive disorders. A few behavioral observations provide grounds for this expectation. In particular, one study showed that adolescents with a substancerelated addiction gave money to charity or the homeless less frequently than their healthy peers (Carter, Johnson, Exline, Post, \& Pagano, 2012). In a complementary vein, animal models show that rats can perform prosocial behaviors such as releasing a cage-mate from a restrainer (Bartal, Decety, \& Mason, 2011), but this ability was no longer observed when those rats were self-administering heroin (Tomek, Stegmann, \& Olive, 2019). Additional research is undoubtedly needed in this area, particularly for humans.

Moreover, prosocialness may vary according to the type of addiction. For instance, alcohol has been demonstrated to disrupt social behaviors (Holman, Ellis, Morgan, \& Weinberg, 2018; Kelly, Day, \& Streissguth, 2000), whereas addiction to nicotine and to cannabis have not (Macleod et al., 2004; Martin \& Sayette, 2018). As to behavioral addictions, problem gambling seems to reduce socialness, particularly when it is carried out online (Griffiths, Parke, Wood, \& Parke, 2005) or on machines (Schüll, 2014). However, these findings did not emerge specifically from measures of prosocialness, and they focused on a single form 
of addiction. Consequently, here too, further comparative research on different addictions is needed.

The present study's purpose was to make up for the scarcity of knowledge about how addiction relates to social dimensions at the behavioral level. Specifically, we aimed to determine whether (1) individuals with addictive disorders reported lower levels of prosocialness than their peers without an addiction, (2) levels of prosocialness varied according to the type of addiction, and (3) levels of prosocialness among individuals with addictive disorders varied according to the number of addictions they had accumulated.

To attain these aims, we analyzed data from the Cohort Study on Substance Use Risk Factors (C-SURF), which incorporates information on a large sample of emerging-adult males. Emerging adulthood is the period in life between 18 and 25 years old, characterized by increasing autonomy and freedom from parental monitoring, and often leading to more sensation-seeking and risk-taking (Arnett, 2000). Indeed, this is the age group most associated with substance use (Schulte \& Hser, 2013). It is, therefore, a very interesting population to examine in the context of addictive behaviors. C-SURF, moreover, included measures of addiction to several substances (e.g., alcohol, nicotine, cannabis) and behaviors (e.g., gambling, gaming). The large sample size and the inclusion of numerous measures lent the present study several advantages of scope. First, they enabled a comparison of different types of addictions within the same sample. Second, they enabled the creation of single-addiction comparison groups. Although addiction to single substances or single behaviors is only representative of a minority of people, examining single addictions can facilitate the discovery of specificities with regards to prosocialness that would otherwise have remained undetected. Third, the use of multiple scales to measure different types of addiction opens up the possibility of investigating the effects of multiple concurrent addictions. Previous research on polysubstance addiction has shown it to be associated with younger age (Kedia, Sell, \& Relyea, 2007), greater impulsivity (Moody, Franck, Hatz, \& Bickel, 2016), and mental health problems (Marmet et al., 2019). With regards to interpersonal relationships, other studies assessing the personality traits of people with addiction concluded that polysubstance users scored higher on antisocial personality traits (Koller, Preuss, Lü, Soyka, \& Pogarell, 2015) and psychoticism (Martinotti, Carli, et al., 2009) than single-substance users. This led us to assume that cumulative addictions may be associated with poorer quality interpersonal relationships. To the best of our knowledge, the relationship between the number of accumulated addictions and prosocialness had never been examined, therefore the present study intended to address the issue.

Our first hypothesis was that emerging-adult males with an addiction would report lower prosocialness than the controls with no addictions. Our second hypothesis was that prosocialness would decrease monotonically (in a doseresponse-like manner) as the number of accumulated addictions increased.

\section{METHODS}

\section{Study design and participants}

Data were drawn from C-SURF's second-wave questionnaire. Switzerland has a mandatory army-recruitment evaluation process for all young Swiss men of around 19 years old. They must attend one of six military recruitment centers to be assigned military or civilian service. This is a unique opportunity to enroll a non-selective sample of young Swiss men. All those reporting to the recruitment centers in Lausanne (French-speaking), Windisch, and Mels (Germanspeaking) between August 2010 and November 2011, were informed of the study and invited to participate. Written consent was obtained from 7,556 young men. C-SURF was independent of army procedures: recruitment centers were used to inform and enroll participants; questionnaires were completed outside the Army context. Full details of the study have been reported previously (Gmel et al., 2015; Studer, Baggio, et al., 2013; Studer, Mohler-Kuo et al., 2013). A total of 6,020 young men $(79.7 \%$ response rate) filled out the second-wave questionnaire between March 2012 and January 2014. Due to missing values on at least one variable of interest, 366 respondents (6.1\% of respondents) were excluded. The final sample for analysis comprised 5,654 participants (93.9\% of respondents).

\section{Measures of addictive disorders}

Alcohol use disorder. Alcohol use disorder (AUD) was measured according to the eleven criteria of the fifth edition of the Diagnostic and Statistical Manual of Mental Disorders (DSM-5; APA, 2013): (1) tolerance; (2) withdrawal symptoms; (3) using larger amounts and for longer periods than intended; (4) continued drinking despite awareness that alcohol repeatedly causes anxiety, depression, or health problems; (5) spending a great deal of time obtaining and consuming alcohol or recovering from the effects of alcohol; (6) giving up important activities because of drinking; (7) desire to cut down alcohol use, without success; (8) continued use despite persistent or recurrent social or interpersonal problems due to drinking; (9) failure to fulfill major role obligations at work/school/home; (10) drinking in hazardous situations; and (11) cravings and urges to consume alcohol. Questions were taken from Knight et al. (2002), and an additional criterion was created for cravings. Participants were asked whether they had experienced each criterion in the previous 12 months. A sum score ranging from 0 to 11 was computed to obtain the number of DSM-5 AUD criteria met. Participants meeting at least four criteria were considered as having AUD, reflecting moderate or more severe AUD according to the DSM-5.

Nicotine dependence. Nicotine dependence (ND) was measured with the Fagerström Test for Nicotine Dependence (FTND; Heatherton, Kozlowski, Frecker, \& Fagerström, 1991), a 6-item screening instrument. Questions included: (1) "How soon after you wake up do you smoke 
your first cigarette?" with response options "0-5 minutes" (coded 3), "6-30 minutes" (coded 2), “31-60 minutes" (coded 1), and "61 minutes or more" (coded 0); (2) "Do you find it difficult to refrain from smoking in places where it is forbidden (e.g., in the library, at the cinema, in restaurants, etc.)?" with response options "yes" (coded 1) and "no" (coded 0); (3) "Which cigarette would you most hate giving up?" with response options "the first one in the morning" (coded 1) and "all the others" (coded 0); (4) "How many cigarettes/day do you smoke?" with response options " $\leq 10$ " (coded 0$)$, “11-20" (coded 1), " $21-30$ " (coded 2), and " $\geq 31$ " (coded 3); (5) "Do you smoke more frequently during the first hours after waking up than during the rest of the day?" with response options "yes" (coded 1) and "no" (coded 0); and (6) "Do you smoke even if you are so ill that you are in bed most of the day?" with response options "yes" (coded 1) and "no" (coded 0 ). A continuous sum score ranging from 0 to 10 was computed as per the authors' proposed scoring procedure. Participants with scores of 3 or more were considered to have ND, corresponding to low or more severe ND (Fagerström, Heatherton, \& Kozlowski, 1990).

Cannabis use disorder. Cannabis use disorder (CUD) was assessed using the Cannabis Use Disorder Identification Test (Adamson \& Sellman, 2003). This 10-item screener asked questions regarding cannabis use and its consequences over the previous 12 months. Continuous scores ranging from 0 to 40 were computed, and participants with scores of 8 or above, according to the authors' scoring procedure, were considered to have CUD.

Gambling disorder. Gambling disorder (GmblD) was measured by asking participants whether they had experienced the nine DSM-5 criteria for GmblD in the previous 12 months (APA, 2013). Questions were taken from the DSMIV's Pathological Gambling Diagnostic Form (Office of Alcoholism and Substance Abuse Services, n.d.). Participants endorsing at least four criteria were considered to have a $\mathrm{GmblD}$, reflecting mild or more severe GmblD according to the DSM-5.

Gaming disorder. Gaming disorder (GD) was assessed using the shortened Game Addiction Scale (GAS; Lemmens, Valkenburg, \& Peter, 2009). The GAS consists of seven items covering the seven criteria of GD, i.e., salience, tolerance, mood modification, withdrawal, relapse, conflict, and problems. Participants evaluated how often they had experienced each criterion over the previous 6 months on a 5point scale ranging from 1 ("never") to 5 ("very often"). As proposed by the authors, a criterion for GD was considered met when participants answered "sometimes", "often", or "very often" (scoring 3, 4, or 5), and GD was defined as meeting four or more of the criteria.

\section{Independent variables}

Types of addiction. We computed the type of addiction as a categorical variable to include the following groups of respondents as its variable modalities: Respondents with no measured addiction to either substances or behaviors (no addiction, $n=3,734)$; respondents detected as having AUD alone $(n=270)$; respondents with ND alone $(n=533)$; respondents with CUD alone $(n=187)$; respondents with GmblD alone $(n=18)$; and respondents with GD alone ( $n$ $=360)$. Respondents with more than one addiction $(n=$ 552 ) were not included in the analyses of the differences between types of addictions.

Number of addictions. The number of addictions corresponded to the sum of substance-related and behavioral addictions which had been identified from respondents' answers. They were recoded into four categories: $0,1,2$, and 3 or more addictions. No addiction (i.e. 0 for any of the analyzed addictions) was used as control group).

\section{Dependent variable}

Prosocialness. Prosocialness was measured using the seven most informative items from the Prosocialness Scale for Adults (PSA; Caprara et al., 2005), as calculated from the item response theory analysis conducted by the authors. The selected items were: "I try to help others", "I am empathetic with those who are in need", "I do what I can to help others avoid getting into trouble", "I intensely feel what others feel", "I try to console those who are sad", "I easily put myself in the shoes of those who are in discomfort", and "I try to be close to and take care of those who are in need". Participants were asked whether each statement was "never/almost never true" (scored 1), "occasionally true" (scored 2), "sometimes true" (scored 3), "often true" (scored 4), and "almost always/ always true" (scored 5). Mean scores ranging from 1 to 5 were computed so that a high score reflected high levels of prosocialness. Internal consistency within the seven items was good (Cronbach's $\alpha=0.89$ ).

\section{Statistical analyses}

Descriptive statistics were calculated to characterize the sample. To test differences in prosocialness between types of addiction, we used analysis of covariance (ANCOVA) with types of addiction as the between-subject factor, adjusted for age, linguistic region, and level of education. To investigate the associations between the number of addictions and prosocialness, we used ANCOVA with the number of addictions as the between-subject factor, again adjusted for age, linguistic region, and level of education. Following these ANCOVA analyses, pairwise comparisons were made between each category of participants (per addiction or for numbers of addictions) and the no addiction control group.

\section{Ethics}

The research protocol (number 15/07) was approved by the Lausanne University Medical School's Ethics Committee for Clinical Research. 


\section{RESULTS}

Descriptive characteristics of the sample are reported in Table 1. The prevalence for ND was highest with $16.7 \%$ of the sample, followed by GD (10.1\%), AUD (9.4\%) and CUD (9.1\%). The lowest prevalence was found for GmblD (1.1\%). $34 \%$ of the sample showed at least one addiction.

\section{Prosocialness according to addiction type}

An ANCOVA revealed the significant effects which different types of addiction had on prosocialness, $F(5$, $5,092)=6.48, P<0.001, \eta_{\mathrm{p}}{ }^{2}=0.006$. Adjusted mean scores for prosocialness and standard errors according to the type of addiction are shown in Fig. 1 and Table 2.

Table 1. Descriptive characteristics of the sample $(N=5,654)$

\begin{tabular}{lcr}
\hline Prosocialness (M, SD) & 3.83 & 0.72 \\
Prevalence of addictions (N, \%) & & \\
$\quad$ AUD & 532 & 9.4 \\
ND & 943 & 16.7 \\
CUD & 514 & 9.1 \\
GmblD & 63 & 1.1 \\
GD & 569 & 10.1 \\
Number of addictions (N, \%) & & \\
0 & 3,734 & 66.0 \\
1 & 1,368 & 24.2 \\
2 & 425 & 7.5 \\
3+ & 127 & 2.2 \\
Age (M, SD) & 21.34 & 1.27 \\
Linguistic region (N, \%) & & \\
$\quad$ French-speaking & 3,210 & 56.8 \\
$\quad$ German-speaking & 2,444 & 43.2 \\
Education (N, \%) & & \\
$\quad$ Primary schooling & 433 & 7.7 \\
$\quad$ Vocational training & 2,611 & 46.2 \\
Post-secondary schooling & 2,610 & 46.2 \\
\hline AUD: Alcohol use disorder
\end{tabular}

AUD: Alcohol use disorder; ND: Nicotine dependence. CUD: Cannabis use disorder; GmblD: Gambling disorder. GD: Gaming disorder. $\mathrm{M}=$ mean; $\mathrm{SD}=$ Standard deviation.

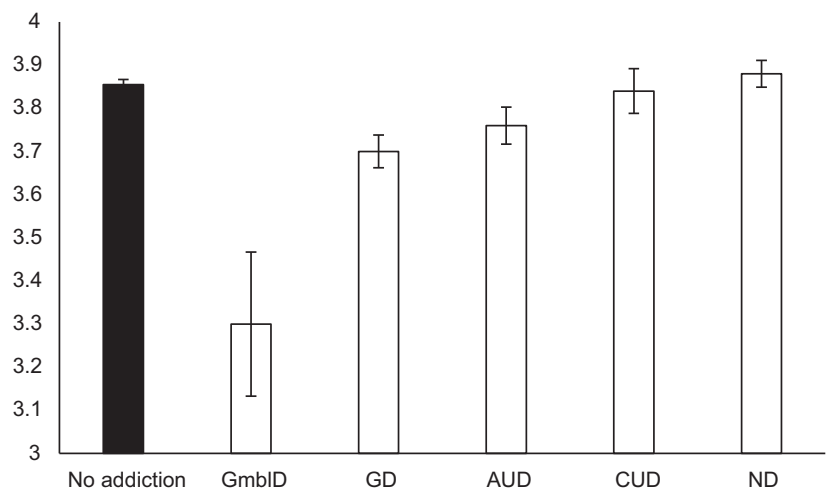

Fig. 1. Adjusted mean scores of prosocialness according to the type of addiction. Error bars represent the standard errors of the means. GmblD: Gambling disorder; GD: Gaming disorder; AUD: Alcohol use disorder; CUD: Cannabis use disorder; ND: Nicotine dependence
Pairwise comparisons with no addiction and between types of addiction are also reported in Table 2. Pairwise comparisons indicated that individuals in the GmblD group reported the lowest scores for prosocialness: They were significantly lower than the scores for all other addiction groups, including the no-addiction group (all $p s \leq 0.019$ ). Individuals in the GD group reported significantly lower scores than the no-addiction, CUD, and ND groups (all $p s$ $\leq 0.030$ ), but significantly higher scores than the GmblD group $(P=0.019)$. The AUD group reported significantly lower scores than the no-addiction and ND groups (all $p s \leq$ 0.028), but significantly higher scores than the GmblD group $(P=0.008)$. The CUD group reported higher scores than the GmblD and GD groups (all $p s \leq 0.030$ ). The ND group reported significantly higher scores than all other groups (all $p s \leq 0.019$ ) except the no-addiction and CUD groups.

\section{Prosocialness according to number of addictions}

A further ANCOVA investigating how different numbers of addictions affected prosocialness yielded a significant effect of number of addictions, $F(3,5,646)=4.79, P=0.002, \eta_{\mathrm{p}}{ }^{2}$ $=0.003$. Adjusted mean scores for prosocialness and their standard errors according to the number of addiction are shown in Fig. 2 and Table 3. Pairwise comparisons are reported in Table 3. As Fig. 2 shows, pairwise comparisons indicated that individuals reporting no addiction had significantly higher scores for prosocialness than those reporting one, two, and three or more addictions (all $p s \leq$ $0.035)$. However, there was no significant difference between participants reporting one, two, and three or more addictions. Even though significant $(P=0.026)$, the linearity of the effect of the number of addictions was weak (linear contrast estimate $=-0.10$ ).

\section{DISCUSSION AND CONCLUSION}

Although the measurement of addictive disorders yielded relatively high prevalence rates overall, they are representative of the population being examined. Switzerland ranks high among Western countries relative to disordered use of alcohol (WHO, 2019), tobacco (WHO, 2018), cannabis (UNODC, 2019; Zobel \& Gmel, 2016), and gaming (Saunders et al., 2017); however, it ranks average by international standards in terms of disordered gambling (Williams, Volberg, \& Stevens, 2012). Moreover, demographics such as young age, being male, and, in Switzerland, residing in a French-speaking region, are associated with even higher addiction prevalence rates. Indeed, this has been observed relative to alcohol (Marmet \& Gmel, 2014), cannabis (Marmet \& Gmel, 2017), and gambling (Billieux et al., 2016). Similarly, in the absence of specific data on gaming in Switzerland, internet usage monitoring has shown higher rates of problematic internet use among 20-24-year-olds, males, and residents of French-speaking regions of Switzerland (Marmet, Notari, \& Gmel, 2015). 
Table 2. Means and standard errors of prosocialness for each addiction group, and pairwise comparison matrix with between-groups contrast estimates $(\mathrm{C})$

\begin{tabular}{|c|c|c|c|c|c|c|c|}
\hline & & & No addiction & GmblD & GD & AUD & CUD \\
\hline & $M$ & $S E$ & & & & & \\
\hline No addiction & 3.86 & 0.012 & - & & & & \\
\hline GmblD & 3.30 & 0.167 & $\begin{aligned} C & =\mathbf{0 . 5 6 0} \\
P & <0.001\end{aligned}$ & - & & & \\
\hline GD & 3.70 & 0.038 & $\begin{aligned} C & =\mathbf{0 . 1 5 9} \\
P & <0.001\end{aligned}$ & $\begin{array}{l}C=\mathbf{0 . 4 0 1} \\
P=0.019\end{array}$ & - & & \\
\hline AUD & 3.76 & 0.043 & $\begin{aligned} \mathrm{C} & =\mathbf{0 . 0 9 8} \\
P & =0.028\end{aligned}$ & $\begin{array}{l}C=\mathbf{0 . 4 6 1} \\
P=0.008\end{array}$ & $\begin{array}{l}C=0.060 \\
P=0.294\end{array}$ & - & \\
\hline CUD & 3.84 & 0.052 & $\begin{array}{l}\mathrm{C}=0.020 \\
P=0.071\end{array}$ & $\begin{aligned} C & =\mathbf{0 . 5 4 0} \\
P & =0.002\end{aligned}$ & $\begin{array}{l}C=\mathbf{0 . 1 3 9} \\
P=0.030\end{array}$ & $\begin{array}{l}C=0.079 \\
P=0.246\end{array}$ & - \\
\hline ND & 3.88 & 0.031 & $\begin{array}{l}\mathrm{C}=0.027 \\
P=0.422\end{array}$ & $\begin{array}{c}C=\mathbf{0 . 5 8 6} \\
P<0.001\end{array}$ & $\begin{array}{c}C=\mathbf{0 . 1 8 5} \\
P<0.001\end{array}$ & $\begin{array}{l}C=\mathbf{0 . 1 2 5} \\
P=0.019\end{array}$ & $\begin{array}{l}C=0.047 \\
P=0.441\end{array}$ \\
\hline
\end{tabular}

Significant contrasts estimates are noted in bold text. GmblD: Gambling disorder; GD: Gaming disorder; AUD: Alcohol use disorder; CUD: Cannabis use disorder; ND: Nicotine dependence. C: Contrast estimates between addiction type in line and addiction type in column.

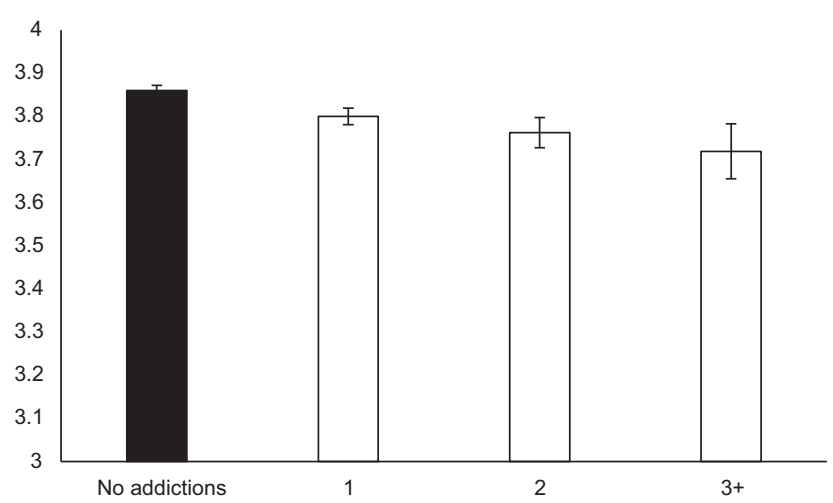

Fig. 2. Adjusted mean scores of prosocialness according to the number of addictions. Error bars represent standard errors of the means

Table 3. Means and standard errors of prosocialness for groups defined by the number of addictions, and pairwise comparison matrix with between-groups contrast estimates (C)

\begin{tabular}{|c|c|c|c|c|c|}
\hline & & & $\begin{array}{c}\text { No } \\
\text { addiction }\end{array}$ & 1 & 2 \\
\hline & $M$ & $S E$ & & & \\
\hline $\begin{array}{l}\text { No } \\
\text { addiction }\end{array}$ & 3.86 & 0.012 & - & & \\
\hline 1 & 3.80 & 0.019 & $\begin{aligned} C & =\mathbf{0 . 0 6 0} \\
P & =0.008\end{aligned}$ & - & \\
\hline 2 & 3.76 & 0.035 & $\begin{array}{l}\mathrm{C}=\mathbf{0 . 0 9 3} \\
P=0.012\end{array}$ & $\begin{array}{l}\mathrm{C}=0.032 \\
P=0.416\end{array}$ & - \\
\hline $3+$ & 3.72 & 0.064 & $\begin{array}{l}\mathrm{C}=\mathbf{0 . 1 3 7} \\
P=0.035\end{array}$ & $\begin{array}{l}\mathrm{C}=0.077 \\
P=0.249\end{array}$ & $\begin{array}{l}C=0.044 \\
P=0.541\end{array}$ \\
\hline
\end{tabular}

Significant contrast estimates are noted in bold text. C: Contrast estimates between addiction type in line and addiction type in column.

We also expected all addiction groups to report fewer prosocial behaviors than the no-addiction control group. The results confirmed this hypothesis for addictions to gambling, gaming, and alcohol. However, they failed to confirm the hypothesis with regards to cannabis and nicotine addictions. These findings were in line with previous reports showing reduced empathy in people with addictions to gambling (Tomei, Besson, \& Grivel, 2017), gaming and the internet (Hui et al., 2019; Jiao, Wang, Peng, \& Cui, 2017; Lachmann et al., 2018), and alcohol (Martinotti, Di Nicola et al., 2009; Maurage et al., 2011). The absence of evidence for a difference between the cannabis addiction group and the no-addiction control group seems to corroborate previous reports that failed to find a clear relationship between cannabis addiction and psychosocial harm (Macleod et al., 2004). Indeed, nowadays, cannabis is increasingly associated with sociability and sharing (Hammersley, Jenkins, \& Reid, 2001). Concerning nicotine addiction, the absence of evidence for any difference from the control group may be because nicotine enhances social functioning (Martin \& Sayette, 2018). Taken broadly, these first results yielded quite a clear distinction between the two behavioral addictions we measured-gambling and gaming-in terms of the level of prosocialness reported. That is, a low level of prosocialness seemed to be more representative of gambling and gaming than did the other substance-related addictions we measured. Several explanations can be proposed. One is that problem gamblers, particularly those who have a preference for machines, tend to suspend social exchange in order to insulate in a private "zone" of interaction with the machine away from other people (Schüll, 2014). Another explanation may be that behavioral addictions are more strongly related to social anxiety disorders than are substance addictions (Marmet et al., 2019). Indeed, social anxiety has been associated with lower levels of prosocialness (Stoltenberg, Christ, \& Carlo, 2013). A final explanation for the lower prosocial behavior associated with gambling and gaming is the competitive nature of these two activities. Both competitive gambling (e.g., poker, sports betting) and competitive video games (after control for violent games) have been shown to predict higher levels of aggression in 
adolescents, particularly males (Adachi \& Willoughby, 2013). Additionally, the use of technologies and the internet to gamble and play games from home may contribute to rendering these activities even less social (Griffiths et al., 2005; Kato, Shinfuku, \& Tateno, 2020; Landau \& Nguyen, 2019). For instance, interacting online in anonymity has been proven to encourage cyberbullying (Lowry, Zhang, Wang, \& Siponen, 2016). Moreover, Hilvert-Bruce and Neill (2020) showed that gamers view aggression in online games as more acceptable than in offline games. The authors also demonstrated that belief in the acceptability of online aggression predicts aggressive and prejudicial behaviors.

Our second hypothesis postulated a monotone decrease in prosocialness as the number of accumulated addictions increased. The analyses yielded significant decreases, in the expected direction, but the decrease across the levels was small. The pairwise comparisons that we performed suggested that it was the presence or absence of addiction which made the difference. In comparison to young men reporting no addiction, those with an addiction reported fewer prosocial behaviors, independently of the number of different addictions they suffered from.

The present study reveals that, at a stage in life when social networks are at their largest (Due, Holstein, Lund, Modvig, \& Avlund, 1999; Morgan, 1988), emerging-adult males with an addiction can show lower levels of prosocialness. It also suggests that these lower levels of prosocialness may not be representative of all addictions. They seem to be particularly prevalent in behavioral addictions, particularly gambling and gaming. Because reduced prosocialness may have a negative impact on an individual's physical and mental health (Anik et al., 2009; Barber \& Erickson, 2001; Caprara et al., 2005), this evidence may be useful for treatment purposes, particularly those that include social reintegration programs (Volkow et al., 2016). Considering individual's prosocial abilities in treatment and social interventions may contribute to reducing their addictive behaviors, enhancing their quality of life, and improving their physical and psychological health.

The present study had two limitations. First, the number of participants with a gambling addiction was small. Second, the results observed could only be generalized to young men. Consequently, further studies should replicate the analyses with a larger sample of gamblers and a heterogeneous sample in terms of sex and age.

There are a few avenues of future research worth mentioning. One possibility would be to extend the examination of the relationship between addiction and prosocialness to other types of addictions. One route worth exploring would be to examine the effects of addictions in terms of social isolation. It would also be interesting to examine whether differences between types of addiction exist in emerging-adult females and older subpopulations. Lastly, research should lead to evaluations of clinical interventions or training to enhance prosocialness in patients with addiction and to measure their effects on addictive behaviors, quality of life, and physical and mental health.
In conclusion, the present study contributed to a better understanding of the relationships between mental health and prosocial behaviors in two ways. First, it showed that the natural human propensity to exhibit behaviors that benefit others might be lower in young men suffering from addiction, despite them being of an age when personal social networks are largest. Second, it revealed that prosocialness seems to be particularly affected by behavioral addictions. This contribution may provide grounds for different prevention levels so that prosocialness could be used as an awareness-raising element for young men and their entourage. It may provide basis for rehabilitation purposes too, to the extent where prosocialness could be considered in social rehabilitation programs, and as a buffer against relapse. In this respect, there is growing interest in remediation programs for social cognition impairments in several fields of psychiatry that focus, among other things, on addressing social functioning impairments in several mental conditions (Fernández-Sotos et al., 2019). Indeed, social skills training programs should be considered for addiction treatment strategies, as they have previously been shown to counteract the addiction rewards on a neurobiological level (Volkow et al., 2011) and to increase the social capital necessary for recovery (Granfield \& Cloud, 2001).

Funding source: This study was supported by the Swiss National Science Foundation (SNSF; Grants FN 33CSC0122679, FN 33CS30_139467).

Authors' contributions: AT: Study concept and design, statistical analyses, data interpretation, drafting the manuscript.

JS: Data preparation, statistical analyses, data interpretation, drafting the manuscript.

GG: Leadership of the C-SURF project, data interpretation, study supervision.

All authors had access to the study data, critically reviewed the manuscript and approved its final version. All authors take responsibility for the data's integrity and the accuracy of the analyses.

Conflicts of interest: The authors declare no conflicts of interest.

Acknowledgments: We are grateful to Céline Gachoud and Christiane Gmel for their precious role in organizing and coordinating data collection. We also thank Prof. Jean-Bernard Daeppen for his comments on the earlier version of the manuscript.

\section{REFERENCES}

Adachi, P. J., \& Willoughby, T. (2013). Demolishing the competition: The longitudinal link between competitive video games, competitive gambling, and aggression. Journal of Youth and Adolescence, 42(7), 1090-1104. https://doi.org/10.1007/s10964013-9952-2. 
Adamson, S. J., \& Sellman, J. D. (2003). A prototype screening instrument for cannabis use disorder: The Cannabis Use Disorders Identification Test (CUDIT) in an alcohol-dependent clinical sample. Drug and Alcohol Review, 22(3), 309-315. https://doi.org/10.1080/0959523031000154454.

Anik, L., Aknin, L. B., Norton, M. I., \& Dunn, E. W. (2009). Feeling good about giving: The benefits (and costs) of self-interested charitable behavior. Harvard Business School Marketing Unit Working Paper (10-012). https://doi.org/10.2139/ssrn.1444831.

APA (2013). Diagnostic and statistical manual of mental disorders. Washington, DC: American Psychiatry Association.

Arnett, J. J. (2000). Emerging adulthood: A theory of development from the late teens through the twenties. American Psychologist, 55(5), 469-480. https://doi.org/10.1037/0003-066X.55.5.469.

Barber, B. K., \& Erickson, L. D. (2001). Adolescent social initiative: Antecedents in the ecology of social connections. Journal of Adolescent Research, 16(4), 326-354. https://doi.org/10.1177/ 0743558401164003.

Bartal, I. B.-A., Decety, J., \& Mason, P. (2011). Empathy and prosocial behavior in rats. Science, 334(6061), 1427-1430. https:// doi.org/10.1126/science.1210789.

Batson, C. D., \& Powell, A. A. (2003). Altruism and prosocial behavior. In T. Millon, M. J. Lerner, \& I. B. Weiner (Eds.), Handbook of psychology (Vol. 5, pp. 463-484). New Jersey: John Wiley \& Sons.

Ben-Ami Bartal, I., Shan, H., Molasky, N. M., Murray, T. M., Williams, J. Z., Decety, J., et al. (2016). Anxiolytic treatment impairs helping behavior in rats. Frontiers in Psychology, 7, 850. https://doi.org/10.3389/fpsyg.2016.00850.

Bethlehem, R. A. I., Allison, C., van Andel, E. M., Coles, A. I., Neil, K., \& Baron-Cohen, S. (2016). Does empathy predict altruism in the wild? Social Neuroscience, 1-8. https://doi.org/10.1080/ 17470919.2016.1249944.

Billieux, J., Achab, S., Savary, J.-F., Simon, O., Richter, F., Zullino, D., et al. (2016). Gambling and problem gambling in Switzerland. Addiction, 111(9), 1677-1683. https://doi.org/10.1111/add.13252.

Black, D. W., Shaw, M. C., McCormick, B. A., \& Allen, J. (2012). Marital status, childhood maltreatment, and family dysfunction: A controlled study of pathological gambling. Journal of Clinical Psychiatry, 73(10), 1293-1297. https://doi.org/10.4088/ JCP. $12 \mathrm{~m} 07800$.

Caprara, G. V., Steca, P., Zelli, A., \& Capanna, C. (2005). A new scale for measuring adults' prosocialness. European Journal of Psychological Assessment, 21(2), 77-89. https://doi.org/10.1027/ 1015-5759.21.2.77.

Carlo, G., Crockett, L. J., Wilkinson, J. L., \& Beal, S. J. (2011). The longitudinal relationships between rural adolescents' prosocial behaviors and young adult substance use. Journal of Youth and Adolescence, 40(9), 1192-1202. https://doi.org/10.1007/s10964010-9588-4.

Carter, R. R., Johnson, S. M., Exline, J. J., Post, S. G., \& Pagano, M. E. (2012). Addiction and "generation me": Narcissistic and prosocial behaviors of adolescents with substance dependency disorder in comparison to normative adolescents. Alcoholism Treatment Quarterly, 30(2), 163-178. https://doi.org/10.1080/ 07347324.2012.663286.

Cotter, J., Granger, K., Backx, R., Hobbs, M., Looi, C. Y., \& Barnett, J. H. (2018). Social cognitive dysfunction as a clinical marker: A systematic review of meta-analyses across 30 clinical conditions. Neuroscience \& Biobehavioral Reviews, 84, 92-99. https:// doi.org/10.1016/j.neubiorev.2017.11.014.

Cousijn, J., Luijten, M., \& Feldstein Ewing, S. W. (2018). Adolescent resilience to addiction: A social plasticity hypothesis. The Lancet Child \& Adolescent Health, 2(1), 69-78. https://doi.org/ 10.1016/S2352-4642(17)30148-7.

Cowlishaw, S., Suomi, A., \& Rodgers, B. (2016). Implications of gambling problems for family and interpersonal adjustment: Results from the quinte longitudinal study. Addiction. https:// doi.org/10.1111/add.13402.

Decety, J. (2010). The neurodevelopment of empathy in humans. Developmental Neuroscience, 32(4), 257-267. https://doi.org/10. $1159 / 000317771$.

Decety, J., Bartal, I. B.-A., Uzefovsky, F., \& Knafo-Noam, A. (2016). Empathy as a driver of prosocial behaviour: Highly conserved neurobehavioural mechanisms across species. Philosophical Transactions of the Royal Society B: Biological Sciences, 371(1686). https://doi.org/10.1098/rstb.2015.0077.

Due, P., Holstein, B., Lund, R., Modvig, J., \& Avlund, K. (1999). Social relations: Network, support and relational strain. Social Science and Medicine, 48(5), 661-673. https://doi.org/10.1016/ S0277-9536(98)00381-5.

Fagerström, K. O., Heatherton, T. F., \& Kozlowski, L. T. (1990). Nicotine addiction and its assessment. Ear, Nose, and Throat Journal, 69(11), 763-765.

Fernández-Sotos, P., Torio, I., Fernández-Caballero, A., Navarro, E., González, P., Dompablo, M., et al. (2019). Social cognition remediation interventions: A systematic mapping review. PloS One, 14(6). https://doi.org/10.1371/journal.pone.0218720.

Ferrari, V., Smeraldi, E., Bottero, G., \& Politi, E. (2014). Addiction and empathy: A preliminary analysis. Neurological Sciences, 35(6), 855-859. https://doi.org/10.1007/s10072-013-1611-6.

Ferris, C. F., Kulkarni, P., Sullivan, J. M., Harder, J. A., Messenger, T. L., \& Febo, M. (2005). Pup suckling is more rewarding than cocaine: Evidence from functional magnetic resonance imaging and three-dimensional computational analysis. The Journal of Neuroscience, 25(1), 149. https://doi.org/10.1523/JNEUROSCI. 3156-04.2005.

Filkowski, M. M., Cochran, R. N., \& Haas, B. W. (2016). Altruistic behavior: Mapping responses in the brain. Neuroscience and Neuroeconomics, 5, 65-75. https://doi.org/10.2147/NAN. S87718.

Fritz, M., El Rawas, R., Salti, A., Klement, S., Bardo, M. T., Kemmler, G., et al. (2011). Reversal of cocaine-conditioned place preference and mesocorticolimbic Zif268 expression by social interaction in rats. Addiction Biology, 16(2), 273-284. https://doi.org/10.1111/j.1369-1600.2010.00285.x.

Gmel, G., Akre, C., Astudillo, M., Bähler, C., Baggio, S., Bertholet, N., et al. (2015). The Swiss cohort study on substance use risk factors-findings of two waves. Sucht, 61(4), 251-262. https:// doi.org/10.1024/0939-5911.a000380.

Gouldner, A. W. (1960). The norm of reciprocity: A preliminary statement. American Sociological Review, 161-178.

Granfield, R., \& Cloud, W. (2001). Social context and "natural recovery": The role of social capital in the resolution of drugassociated problems. Substance Use and Misuse, 36(11), 15431570. https://doi.org/10.1081/JA-100106963. 
Griffiths, M., Parke, A., Wood, R., \& Parke, J. (2005). Internet gambling: An overview of psychosocial impacts. UNLV Gaming Research \& Review Journal, 10(1), 27-39.

Hammersley, R., Jenkins, R., \& Reid, M. (2001). Cannabis use and social identity. Addiction Research \& Theory, 9(2), 133-150. https://doi.org/10.3109/16066350109141745.

Heatherton, T. F., Kozlowski, L. T., Frecker, R. C., \& Fagerström, K.-O. (1991). The Fagerström test for nicotine dependence: A revision of the Fagerström tolerance questionnaire. British Journal of Addiction, 86(9), 1119-1127. https://doi.org/10.1111/ j.1360-0443.1991.tb01879.x.

Hilvert-Bruce, Z., \& Neill, J. T. (2020). I'm just trolling: The role of normative beliefs in aggressive behaviour in online gaming. Computers in Human Behavior, 102, 303-311. https://doi.org/ 10.1016/j.chb.2019.09.003.

Holman, P. J., Ellis, L., Morgan, E., \& Weinberg, J. (2018). Prenatal alcohol exposure disrupts male adolescent social behavior and oxytocin receptor binding in rodents. Hormones and Behavior, 105, 115-127. https://doi.org/10.1016/j.yhbeh. 2018.08.004.

Homer, B. D., Solomon, T. M., Moeller, R. W., Mascia, A., DeRaleau, L., \& Halkitis, P. N. (2008). Methamphetamine abuse and impairment of social functioning: A review of the underlying neurophysiological causes and behavioral implications. Psychological Bulletin, 134(2), 301-310. https://doi.org/10.1037/ 0033-2909.134.2.301.

Hui, B. P., Wu, A. M., \& Pun, N. (2019). Disentangling the effects of empathy components on Internet gaming disorder: A study of vulnerable youth in China. Journal of Behavioral Addictions, 8(1), 181-189. https://doi.org/10.1556/2006.8.2019.12.

Hulka, L. M., Preller, K. H., Vonmoos, M., Broicher, S. D., \& Quednow, B. B. (2013). Cocaine users manifest impaired prosodic and cross-modal emotion processing. Frontiers in Psychiatry, 4, 98. https://doi.org/10.3389/fpsyt.2013.00098.

Jiao, C., Wang, T., Peng, X., \& Cui, F. (2017). Impaired empathy processing in individuals with internet addiction disorder: An event-related potential study. Frontiers in Human Neuroscience, 11, 498-498. https://doi.org/10.3389/fnhum.2017.00498.

Kato, T. A., Shinfuku, N., \& Tateno, M. (2020). Internet society, internet addiction, and pathological social withdrawal: the chicken and egg dilemma for internet addiction and hikikomori. Current Opinion in Psychiatry, 33(3), 264-270. https:// doi.org/10.1097/YCO.0000000000000601.

Kedia, S., Sell, M. A., \& Relyea, G. (2007). Mono- versus polydrug abuse patterns among publicly funded clients. Substance Abuse Treatment, Prevention, and Policy, 2(33). https://doi.org/10. 1186/1747-597X-2-33.

Kelly, S. J., Day, N., \& Streissguth, A. P. (2000). Effects of prenatal alcohol exposure on social behavior in humans and other species. Neurotoxicology and Teratology, 22(2), 143-149. https://doi.org/10.1016/S0892-0362(99)00073-2.

Klein, N. (2017). Prosocial behavior increases perceptions of meaning in life. The Journal of Positive Psychology, 12(4), 354361. https://doi.org/10.1080/17439760.2016.1209541.

Knight, J. R., Wechsler, H., Kuo, M., Seibring, M., Weitzman, E. R., \& Schuckit, M. A. (2002). Alcohol abuse and dependence among US college students. Journal of Studies on Alcohol, 63(3), 263-270. https://doi.org/10.15288/jsa.2002.63.263.
Koller, G., Preuss, U., Lü, O., Soyka, M., \& Pogarell, O. (2015). Alcohol-Dependent subjects show different personality traits compared with subjects with multiple substance dependence: preliminary data. Journal of Addiction Medicine, 9(4), 257-260. https://doi.org/10.1097/adm.0000000000000126.

Lachmann, B., Sindermann, C., Sariyska, R. Y., Luo, R., Melchers, M. C., Becker, B., et al. (2018). The role of empathy and life satisfaction in internet and smartphone use disorder. Frontiers in Psychology, 9(398). https://doi.org/10.3389/fpsyg.2018.00398.

Landau, S., \& Nguyen, T. (2019). Effects of gaming on children's brains: Depression and social isolation. Advances in Social Sciences Research Journal, 6(9), 291-302. https://doi.org/10. 14738/assrj.69.4856.

Lemmens, J. S., Valkenburg, P. M., \& Peter, J. (2009). Development and validation of a game addiction scale for adolescents. Media Psychology, 12(1), 77-95. https://doi.org/10.1080/ 15213260802669458.

Liu, Y., Young, K. A., Curtis, J. T., Aragona, B. J., \& Wang, Z. (2011). Social bonding decreases the rewarding properties of amphetamine through a dopamine D1 receptor-mediated mechanism. The Journal of Neuroscience, 31(22), 7960. https:// doi.org/10.1523/JNEUROSCI.1006-11.2011.

Lockwood, P. L., Apps, M. A., Valton, V., Viding, E., \& Roiser, J. P. (2016). Neurocomputational mechanisms of prosocial learning and links to empathy. Proceedings of the National Academy of Sciences, 113(35), 9763-9768. https://doi.org/10.1073/pnas. 1603198113.

Lowry, P. B., Zhang, J., Wang, C., \& Siponen, M. (2016). Why do adults engage in cyberbullying on social media? An integration of online disinhibition and deindividuation effects with the social structure and social learning model. Information Systems Research, 27(4), 962-986. https://doi.org/10.1287/isre.2016. 0671.

Macleod, J., Oakes, R., Copello, A., Crome, I., Egger, M., Hickman, M., et al. (2004). Psychological and social sequelae of cannabis and other illicit drug use by young people: A systematic review of longitudinal, general population studies. The Lancet, 363(9421), 1579-1588. https://doi.org/10.1016/S0140-6736(04) 16200-4.

Marmet, S., \& Gmel, G. (2014). Suchtmonitoring Schweiz-Alkoholkonsumstörungen im Jahr 2013. Lausanne: Sucht Schweiz.

Marmet, S., \& Gmel, G. (2017). Suchtmonitoring Schweiz-Themenheft zum problematischen Cannabiskonsum in der Schweiz im Jahr 2016. Lausanne: Sucht Schweiz.

Marmet, S., Notari, L., \& Gmel, G. (2015). Suchtmonitoring Schweiz-Themenheft Internetnutzung und problematische Internetnutzung in der Schweiz im Jahr 2015. Lausanne: Sucht Schweiz.

Marmet, S., Studer, J., Wicki, M., Bertholet, N., Khazaal, Y., \& Gmel, G. (2019). Unique versus shared associations between self-reported behavioural addictions and substance use disorders and mental health problems: A commonality analysis in a large sample of young Swiss men. Journal of Behavioral Addictions, 8(14), 664-677. https://doi.org/10.1556/2006.8.2019.70.

Martin, L. M., \& Sayette, M. A. (2018). A review of the effects of nicotine on social functioning. Experimental and Clinical Psychopharmacology, 26(5), 425-439. https://doi.org/10.1037/ pha0000208. 
Martinotti, G., Carli, V., Tedeschi, D., Di Giannantonio, M., Roy, A., Janiri, L., et al. (2009). Mono- and polysubstance dependent subjects differ on social factors, childhood trauma, personality, suicidal behaviour, and comorbid Axis I diagnoses. Addictive Behaviors, 34(9), 790-793. https://doi.org/10.1016/j.addbeh. 2009.04.012.

Martinotti, G., Di Nicola, M., Tedeschi, D., Cundari, S., \& Janiri, L. (2009). Empathy ability is impaired in alcohol-dependent patients. American Journal on Addictions, 18(2), 157-161. https:// doi.org/10.1080/10550490802544391.

Maurage, P., Grynberg, D., Noel, X., Joassin, F., Philippot, P., Hanak, C., et al. (2011). Dissociation between affective and cognitive empathy in alcoholism: A specific deficit for the emotional dimension. Alcoholism: Clinical and Experimental Research, 35(9), 1662-1668. https://doi.org/10.1111/j.15300277.2011.01512.x.

Moll, J., Krueger, F., Zahn, R., Pardini, M., de Oliveira-Souza, R., \& Grafman, J. (2006). Human fronto-mesolimbic networks guide decisions about charitable donation. Proceedings of the National Academy of Sciences of the United States of America, 103(42), 15623-15628. https://doi.org/10.1073/pnas. 0604475103.

Moody, L., Franck, C., Hatz, L., \& Bickel, W. K. (2016). Impulsivity and polysubstance use: A systematic comparison of delay discounting in mono-, dual-, and trisubstance use. Experimental and Clinical Psychopharmacology, 24(1), 30-37. https://doi.org/ 10.1037/pha0000059.

Morgan, D. L. (1988). Age differences in social network participation. Journal of Gerontology, 43(4), S129-S137. https://doi. org/10.1093/geronj/43.4.S129.

Pagano, M. E., Friend, K. B., Tonigan, J. S., \& Stout, R. L. (2004). Helping other alcoholics in alcoholics anonymous and drinking outcomes: Findings from project MATCH. Journal of Studies on Alcohol, 65(6), 766-773. https://doi.org/10.15288/jsa.2004. 65.766.

Pelloux, Y., Giorla, E., Montanari, C., \& Baunez, C. (2019). Social modulation of drug use and drug addiction. Neuropharmacology, 159, 107545. https://doi.org/10.1016/j.neuropharm.2019. 02.027 .

Porcelli, S., Van Der Wee, N., van der Werff, S., Aghajani, M., Glennon, J. C., van Heukelum, S., et al. (2019). Social brain, social dysfunction and social withdrawal. Neuroscience \& Biobehavioral Reviews, 97, 10-33. https://doi.org/10.1016/j. neubiorev.2018.09.012.

Post, S. G. (2005). Altruism, happiness, and health: it's good to be good. International Journal of Behavioral Medicine, 12(2), 6677. https://doi.org/10.1207/s15327558ijbm1202_4.

Preller, K. H., Hulka, L. M., Vonmoos, M., Jenni, D., Baumgartner, M. R., Seifritz, E., et al. (2014). Impaired emotional empathy and related social network deficits in cocaine users. Addiction Biology, 19(3), 452-466. https://doi.org/10.1111/ adb.12070.

Preston, S. D. (2013). The origins of altruism in offspring care. Psychological Bulletin, 139(6), 1305-1341. https://doi.org/10. 1037/a0031755.

Saunders, J. B., Hao, W., Long, J., King, D. L., Mann, K., FauthBühler, M., et al. (2017). Gaming disorder: Its delineation as an important condition for diagnosis, management, and prevention. Journal of Behavioral Addictions, 6(3), 271-279. https://doi.org/10.1556/2006.6.2017.039.

Schüll, N. D. (2014). Addiction by design: Machine gambling in Las Vegas. Princeton: Princeton University Press.

Schultz, W. (2016). Dopamine reward prediction error coding. Dialogues in Clinical Neuroscience, 18(1), 23-32.

Schulte, M. T., \& Hser, Y.-I. (2013). Substance use and associated health conditions throughout the lifespan. Public Health Reviews, 35(2), 3. https://doi.org/10.1007/ BF03391702.

Stoltenberg, S. F., Christ, C. C., \& Carlo, G. (2013). Afraid to help: Social anxiety partially mediates the association between 5HTTLPR triallelic genotype and prosocial behavior. Social Neuroscience, 8(5), 400-406. https://doi.org/10.1080/17470919. 2013.807874.

Studer, J., Baggio, S., Mohler-Kuo, M., Dermota, P., Gaume, J., Bertholet, N., et al. (2013). Examining non-response bias in substance use research-Are late respondents proxies for non-respondents? Drug and Alcohol Dependence, 132(1), 316-323. https://doi.org/10.1016/j.drugalcdep.2013. 02.029 .

Studer, J., Mohler-Kuo, M., Dermota, P., Gaume, J., Bertholet, N., Eidenbenz, C., et al. (2013). Need for informed consent in substance use studies-Harm of bias? Journal of Studies on Alcohol and Drugs, 74(6), 931-940. https://doi.org/10.15288/ jsad.2013.74.931.

Tomei, A., Besson, J., \& Grivel, J. (2017). Linking empathy to visuospatial perspective-taking in gambling addiction. Psychiatry Research, 250, 177-184. https://doi.org/10.1016/j.psychres.2016. 12.061 .

Tomei, A., Besson, J., Reber, N., Rougemont-Bücking, A., \& Grivel, J. (2017). Personal distress and empathic concern in methadone-maintained patients. Journal of Substance Use, 22(1), 37-41. https://doi.org/10.3109/14659891.2016. 1140238 .

Tomek, S. E., \& Olive, M. F. (2018). Chapter four - social influences in animal models of opiate addiction. International Review of Neurobiology, 140, 81-107. https://doi.org/10.1016/bs.irn.2018. 07.004.

Tomek, S. E., Stegmann, G. M., \& Olive, M. F. (2019). Effects of heroin on rat prosocial behavior. Addiction Biology, 24(4), 676684. https://doi.org/10.1111/adb.12633.

UNODC (2019). World drug report 2019. Geneva: United Nations.

Volkow, N. D., Baler, R. D., \& Goldstein, R. Z. (2011). Addiction: Pulling at the neural threads of social behaviors. Neuron, 69(4), 599-602. https://doi.org/10.1016/j.neuron.2011.01. 027.

Volkow, N. D., Koob, G. F., \& McLellan, A. T. (2016). Neurobiologic advances from the brain disease model of addiction. New England Journal of Medicine, 374(4), 363-371. https://doi. org/10.1056/NEJMra1511480.

WHO (2018). WHO global report on trends in prevalence of tobacco smoking 2000-2025. Geneva: World Health Organization.

WHO (2019). Global status report on alcohol and health 2018. Geneva: World Health Organization.

Williams, R. J., Volberg, R. A., \& Stevens, R. M. G. (2012). The population prevalence of problem gambling: Methodological 
influences, standardized rates, jurisdictional differences, and worldwide trends. Ontario: Ontario Problem Gambling Research Centre.

Young, K. A., Gobrogge, K. L., \& Wang, Z. (2011). The role of mesocorticolimbic dopamine in regulating interactions between drugs of abuse and social behavior. Neuroscience \& Biobehavioral Reviews, vo35(3), 498-515. https://doi.org/10.1016/j. neubiorev.2010.06.004.

Zobel, F., \& Gmel, G. (2016). Monitorage des addictions avec les pays voisins: le cannabis. Lausanne: Addictions Suisse. 